\title{
A Community Science Approach to Conservation Challenges Posed by Rebounding Marine Mammal Populations: Seal-Fishery Interactions in New England
}

\author{
Andrea Bogomolni ${ }^{1 * \dagger}$, Owen C. Nichols ${ }^{2,3+}$ and Dee Allen ${ }^{4,5}$ \\ ${ }^{1}$ Massachusetts Maritime Academy, Marine Science, Safety and Environmental Protection, Buzzards Bay, MA, \\ United States, ${ }^{2}$ Department of Ecology, Center for Coastal Studies, Provincetown, MA, United States, ${ }^{3}$ Biology Department, \\ Woods Hole Oceanographic Institution, Woods Hole, MA, United States, ${ }^{4}$ U.S. Marine Mammal Commission, Bethesda, \\ MD, United States, ${ }^{5}$ Vertebrate Zoology, Smithsonian Institution, National Museum of Natural History, Washington, DC, \\ United States
}

OPEN ACCESS

Edited by:

Silvio Marchini,

University of São Paulo, Brazil

Reviewed by:

Matthew Grainger,

Norwegian Institute for Nature

Research (NINA), Norway

Shelly L. Volsche,

Boise State University, United States

*Correspondence:

Andrea Bogomolni abogomolni@gmail.com

tThese authors have contributed equally to this work and share first authorship

Specialty section:

This article was submitted to

Human-Wildlife Dynamics,

a section of the journal

Frontiers in Conservation Science

Received: 16 April 2021

Accepted: 30 June 2021

Published: 29 July 2021

Citation:

Bogomolni A, Nichols OC and Allen D (2021) A Community Science Approach to Conservation Challenges

Posed by Rebounding Marine

Mammal Populations: Seal-Fishery

Interactions in New England.

Front. Conserv. Sci. 2:696535.

doi: 10.3389/fcosc.2021.696535
Between 1880-1962, gray and harbor seals were targeted in legal seal bounty hunts across Maine and Massachusetts due to a perceived competition with commercial fisheries. Following their extirpation 50 years ago, legislative protections allowed seals to recolonize historical grounds along the New England coast. With this conservation success story, conflict has re-emerged as seen in the numerous media articles reflecting a temperament beckoning to the past century, with calls to cull the population and the spread of misinformation. The return of seals after decades of near-absence has created a new ecological and psychological baseline for New Englanders where for three generations, seals were rarely present. Although seals are statutorily protected species, unlike the tools and resources available for depleted, threatened or endangered species, the support needed to increase opportunities for coexistence of humans with rebounding pinnipeds, are comparatively lacking. Even as gray seals have the highest fisheries bycatch levels of any marine mammal in the U.S., resources to address these management challenges are minimal due to limitations and prioritization processes for committing available support. While seal conservation has been a success, the manner in which management is often separately applied to ecosystem elements (e.g., harvested species, protected species) contributes to knowledge gaps, and a disconnect between the goals of conservation to sustainably utilize natural resources while also protecting the intrinsic value of resources for ecosystem health. Solutions to such coexistence challenges could benefit from a more holistic ecosystem conservation approach. To address these disconnects, a two-day workshop was convened to understand seal-fishery interactions where we provided opportunities for community members to meet and learn from one another including, but not limited to, fishermen, natural resource managers, marine mammal stranding response personnel and scientists. A convening that might otherwise result in tumultuous and adversarial engagement, we used as a tool to engage. This community science approach led to long-term relationships that have allowed for successful applied, and community driven, solutions. 
Here we share the lessons learned and subsequent partnerships. Our intent is to share our approach to address other marine mammal conservation conflict challenges, allowing for collaborative pathways toward long-term coexistence.

Keywords: seals, fisheries, coexistence, community science, conflict, collaborative research

\section{INTRODUCTION}

Fishery interactions are a critical concern for marine mammal populations and ecosystem health, as well as a challenge for sustainable fisheries practices. Conflicts surrounding rebounding marine mammals and fisheries are common in marine systems (Nyhus, 2016, Guerra, 2019).

Interactions between marine mammals and fisheries are generally classified as operational (also referred to as direct or technical), in which marine mammals interact directly with a fishing operation; and indirect (or ecological), during which larger-scale competition or other trophic interactions occur among fisheries and marine mammal populations (Gulland, 1986; Plagányi and Butterworth, 2005). Depredation is a form of operational interaction in which marine mammals remove or damage fish captured in fishing gear, reducing the amount of landed or marketable catch. Depredation can have significant economic costs for some fisheries from lost/damaged catch and gear damage, and can cause injury or mortality to the predator from interaction with gear or deterrence methods (Read, 2005, 2008; Götz and Janik, 2013). Bycatch, or unintended catch of non-target species, is another form of operational interaction, currently the primary cause of serious injury and mortality for marine mammals globally (Read et al., 2006). Addressing issues surrounding bycatch and depredation will help maintain sustainable fisheries and practices as well as help address the challenges of recovering and rebounding pinniped populations. In order to best address the issue, actors from all sides of the conflict need to work together as collaborators to navigate and address interactions.

As ocean use increases and we consider truly embracing ecosystem-based management, addressing the challenges that are arising with rebounding populations of protected marine mammal species must become a priority (Roman et al., 2015, Cammen et al., 2019). If we do not, we may once again as in the era of seal bounty hunting, reach a sociological tipping point where politicized perception, rather than sound science and holistic ecosystem-based management objectives, will be sought to solve conflict. Dialogue must allow for full participation, sharing of knowledge and honest discussion that respects divergent views and perspectives to address the underlying conflict (Zimmermann et al., 2020).

As we attempt to address conflicts arising with rebounding populations of seals, community partnerships often need to have an opportunity created by trusted partners, where values can be respected. Community science applies the scientific method to social inquiry that is democratic, communitydriven and community-controlled, characterized by placebased knowledge and social learning, collective action and empowerment (Salomon et al., 2018, Charles et al., 2020). This approach is necessary if we are to address conflicts and provide concrete and productive solutions for co-existence. We present here a case study of a community science approach taken to proactively address the seal-fishery conflict on Cape Cod, Massachusetts that is equitable, community-based and designed to respect all involved. The following are our experiences from convening this workshop, lessons learned, and progress made since our workshop, followed by recommendations for furthering these efforts.

\section{Context in Which the Innovation Occurs}

Nearly extirpated only 50 years ago, rebounding populations of gray and harbor seals are now a northeast U.S. marine mammal conservation success story. Between 1888 and 1962, an estimated 72,000 and 135,000 seals were reported killed by bounty hunters on the Maine and Massachusetts coast due to perceived competition with commercial fisheries (Lelli et al., 2009). As late as 1962, a five-dollar bounty was paid in Massachusetts per nose of each recovered seal. The bounty hunts devastated the U.S. populations of harbor and gray seals and resulted in the near extirpation of gray seals in the U.S. by the early 1960s (Katona et al., 1993; Wood et al., 2020). Following Massachusetts state protection 1965 and the passage of the Marine Mammal Protection Act (MMPA) in 1972, gray seals and harbor seals repopulated their historical grounds, with a current estimate of 27,000 gray seals and 75,000 harbor seals in U.S. waters (Hayes et al., 2019). As the first U.S. congressional legislation mandating an ecosystembased approach to marine resource management, the primary objective of marine mammal management under the MMPA is to maintain the health and stability of the marine ecosystem. While conservationists celebrate this success, the increased presence of seals in New England has created unique challenges (Bogomolni et al., 2010; Roman et al., 2015; Jackman et al., 2018). For some, the populations of seals are "exploding," and the "seals are like vermin" (Boston Magazine, 2013; Nantucket Chronicle, 2013). Calls for culls and management action against seals have resumed, echoing similar sentiments of the 1800s.

The fishing community in New England has identified bycatch and depredation by harbor and gray seals as an issue of concern (Nichols et al., 2012; Rafferty et al., 2012). Gray seals in particular are of interest as their recolonization sites coincide with historically important fishing grounds in the region. According to the Northeast Fisheries Science Center (2020), "Fisheries interactions have also increased over the past two decades, with fewer than 10 total estimated gray seal interactions in 1993, to more than 1,000 annually in four out of the last five years; this is the highest bycatch of any U.S. marine mammal species."

In seal-fisheries conflicts, it is often the case that the limitation to finding solutions are impeded by adverse human-human 
relationships and underlying presumptions directed at one group (of humans) over another (Pooley et al., 2017). While many of these challenges may ultimately be addressed by forming research questions and creating platforms to collect data to direct science, management and policy, the first step in addressing this conflict is to define who is in our community, and engage all actors from the beginning of these efforts (Redpath et al., 2013). Stakeholders in a process are actors (persons or organizations) with a vested interest (Schmeer, 1999). In this controversy, we look to the relationships between actors in our community including, but not limited to, fishermen ${ }^{1}$, natural resource (marine mammal and fisheries) managers, marine mammal stranding response personnel and research scientists.

\section{Detail to Understand Key Programmatic Elements}

Community science partnerships allow the opportunity to provide technical support and knowledge collectively. Our approach to address seal bycatch and depredation was based on authentic engagement and community science over nearly a decade. As we developed opportunities for engagement over the years and the agenda for the 2015 workshop, we kept in mind four objectives: 1) Address the disconnect 2) Build trust 3) Build community, and most important 4) Commit to the long term.

1) Address the Disconnect. Community science requires an engagement approach with an emphasis on asking questions, listening to concerns, and doing so in an environment in which community members feel comfortable speaking freely.

2) Build Trust. We are all human and must acknowledge that each actor's professional persona belongs to an individual citizen with personal motivations, ideologies and experiences outside of ones' professional occupation. Meetings began with a clear outline of expectations for decorum, ample refreshments, and time for casual conversation.

3) Build Community It is important to bring science and management into community and community into the science and management. Our goal was not to pre-define the results or the recommendations that emerged. Listen to community discussions and from there, seek to fill knowledge gaps through building bridges between those with expertise and those with questions. All participants were valued and respected for their expertise and knowledge in their own fields. We designed a day-long series of presentations and hands-on activities that would facilitate learning, sharing and building relationships.

4) Commit to the Long Term. Recognize that all of the above three approaches require time, dedication, and investment in each relationship. Developing avenues for conversation shows commitment and desire to continue relationship building. This applies to the sciences as well.

\footnotetext{
${ }^{1}$ In the case study reported herein, fishing community members self-identified as 'fishermen' irrespective of their gender identity, so we have chosen to use their preferred term.
}

Engagement in these efforts began years before this workshop through a series of small meetings (Bogomolni et al., 2010). Following recommendations from these meetings, outreach was conducted in Cape Cod (Massachusetts, USA) fishing communities to connect researchers with commercial and recreational fishermen, building the foundation for cooperative research partnerships. Local researchers met with fishermen at harbors and community centers, volunteered as crew on fishing vessels, and attended relevant fishery association and management meetings. This collective and individual outreach effort was highly successful, laying the groundwork for numerous collaborative research projects involving fishing community partners. All research projects involved fishing community partners at the earliest stages of project development, which is key to building mutual trust and understanding among all parties, as well as laying the foundation for sound, hypothesis-driven science (Nichols, 2011).

Subsequently, a diverse group of over 60 commercial and recreational fishermen, scientists, and resource managers gathered at the Center for Coastal Studies (CCS) for the workshop, "Gulf of Maine Seals: Fisheries Interactions and Integrated Research," to discuss operational and ecological interactions between seals and fisheries. In order to ensure that the fishing community had a distinct voice, a forum was included in the workshop agenda, during which fishermen were encouraged to share their observations, experiences and concerns. The recommendations from all participants shared common themes, including the need for collaborative research involving both the scientific and fishing communities. Workshop organizers proposed a consortium to foster collaboration among managers, researchers and the fishing community (Nichols et al., 2012), which became the Northwest Atlantic Seal Research Consortium (nasrc.whoi.edu/sealconsortium.org). Our ongoing partnerships between scientists and fishermen studying seal/fisheries interactions (e.g., Nichols et al., 2014) helped leverage broader communication and collaboration across the fishing community, laying not only the foundation for future research, but also broadening the community conversations around issues of depredation, bycatch, and other interactions (Cammen et al., 2019). We worked to connect students with fishermen to conduct collaborative research projects on various aspects of seal/fisheries interactions, which added new perspectives to these community conversations (e.g., Sirak, 2015):

\footnotetext{
"As a guest on the boat and a scientist, it is important to make compromises. You are already imposing on the fishermen by taking up extra room on the boat and by interfering with the standard fishing process at times. It is important to know when to draw the line. For example, I was able to stay out of the way while still counting each skate and bycaught animal that came up in the net. I was also able to record and photograph most of the damage done to the catch during the haul while still staying out of the way. However, I was not able to bring back any bycaught seals for necropsy as I originally had wanted to. While I asked the captain if we could bring bycaught seals back multiple times, I eventually realized that this was too much to ask of him. From the
} 
BOX 1 | Objectives of the Workshop.

The primary objectives of the workshop were to:

1. Build a bridge between the fisheries, science and regulatory communities based on each group's expertise and experiences.

2. Gain a better understanding of the types of fisheries interactions that occur in the Gulf of Maine and Mid-Atlantic regions and how they may present (be visible) in case studies.

3. Discuss the benefits gained by all from providing marine mammal fishery bycatch to researchers, including the ability to learn about the overall health of a population, the animals' diets, and ecosystem health.

Through fulfilling these objectives, we strove to:

1. Reduce the adversarial nature between groups by working together to mitigate harmful marine animal/fishing gear interactions and learn from them when they do occur.

2. Work with regulators (through permitting process or other means) to increase positive relationships (e.g. collaborative research) that provide benefit to all groups.

3. Identify ways to reduce bycatch and injury to marine animals by the fishing community.

scientific perspective, each seal we dumped back overboard was an animal full of information we would never be able to get back, but from a fishermen's perspective each seal was a smelly waste of time that already damaged their gear and their catch and would take up too much space on the boat and draw too much attention from the tourists back in Chatham."-Laura Sirak, University of New England graduate student conducting research on seal bycatch and depredation (Sirak, 2015).

After extensive outreach and based on community feedback, we convened this two-day workshop to address disconnect and knowledge gaps among those involved in the fishing, marine mammal research and fisheries management (Box 1). The case study presented is based on our observations and insights. We intended to create a group learning experience in order to come to a greater common understanding of the causes and effects of, and lessons learned from, interactions between seals and fisheries, with a particular focus on knowledge gained from carcasses of bycatch.

The workshop took place December 1-2, 2015 in Chatham and Woods Hole, MA. The workshop locations were chosen with the intent of welcoming participants onto the "home turf" of the fishing and scientific communities, creating new experiences while also maintaining the comfort associated with surroundings familiar to community members. Individuals and/or organizations were invited based on previous engagement events or, as those identified as missing from previous discussions. This workshop consisted of a half day dedicated to introductory presentations to understand the perspectives and importance of marine mammals in the fishing, stranding and management communities, followed by a hands-on classroom and dockside practical to learn about fishing and gear from fishery observers and the fishing community, and concluded with an informal social gathering at a restaurant. The second day involved necropsies of stranded and bycaught seals with all attendees (including fishermen, scientists, marine mammal stranding responders and managers) and a synthesis of the workshop.

\section{WORKSHOP APPROACH}

\section{Day 1 Agenda (Chatham Community Center, Chatham Fish Pier)}

Following introductions, presentations were given on a range of topics, including assessment of injuries from fisheries interactions in stranded marine mammals, description of regional fisheries (e.g., gear types, fishing practices), rationale for and data collection in the fishery observer program, and fishing industry perspectives on seal/fishery interactions and collaborative research. Next, fishermen and fishery observer trainers led a hands-on demonstration and group discussion of fishing gear and fishing practices (Figure 1). Workshop attendees then traveled to the Chatham Fish Pier for a dockside examination and discussion onboard two commercial fishing vessels (Figure 2). Through in-person demonstrations, workshop attendees were able to develop a working understanding of fishing gear and fishing practices from experts in a manner otherwise unattainable in an academic setting.

\section{Day 1 Summary}

Despite the diverse and broad range of perspectives, participants expressed many common values, including the need for healthy marine ecosystems, concern for animal welfare, regulatory compliance, and the economic and cultural value of fisheries. The level of open, candid communication that took place during the afternoon and evening discussions indicated a great deal of mutual respect among participants and highlighted the value 


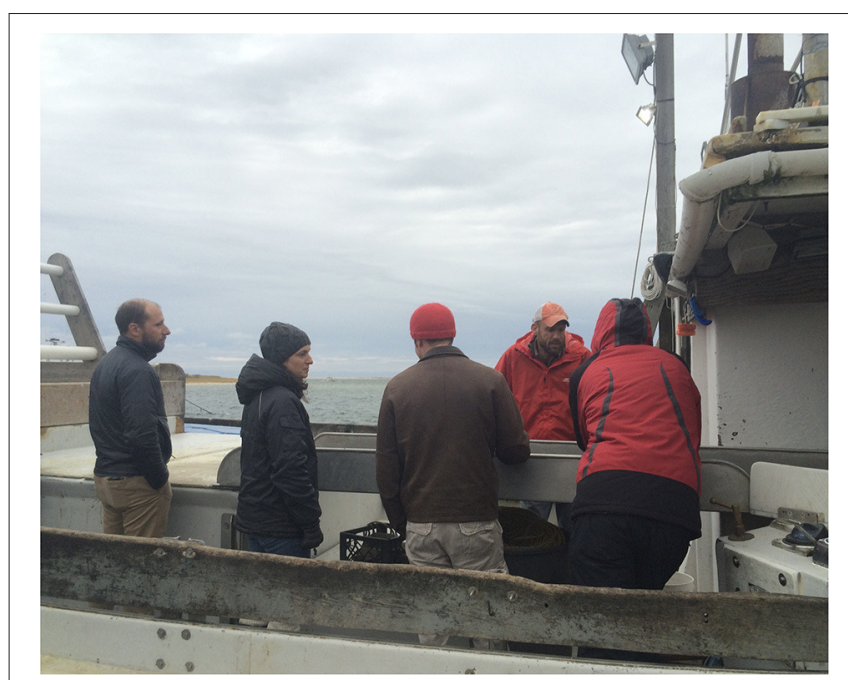

FIGURE 1 | Workshop participants traveled to the Chatham Fish Pier for a dockside examination and discussion on board two commercial fishing vessels, a demersal longliner or "tub trawler" (FN Noah) and a gillnetter (FN Dawn T). Here, a commercial fisherman explains the inner workings of a gillnet fishing boat to several marine mammal researchers and marine mammal stranding network personnel. of the workshop, designed to include dedicated opportunities for conversation, as a vehicle for building community and collaboration. Fishermen highlighted the importance of mutual respect as an incentive for increased communication with the fishing community, along with involvement of fishermen in research and management.

Fishing community participants suggested starting with a small group of researchers and fishermen to allow building of trust and mutual understanding. Among the specific ideas posed by the group was the potential application of novel acoustic deterrents to reduce interactions between seals and fishing gear, as well as specialized tools to safely release entangled seals from fishing gear while minimizing seal injury and gear damage. Some discussion centered on the availability of newly authorized acoustic deterrent technology and potential collaborative research to test its efficacy in local inshore fisheries.

\section{Day 2 Agenda (Woods Hole Oceanographic Institution Marine Research Facility)}

Participants followed safety protocols and were encouraged to actively participate in the necropsies of two bycaught seals and one stranded seal. This unique exercise enabled participants to: learn key morphological traits used to identify harbor and gray seals; assess carcasses to distinguish signs of fishery-related mortality from other causes of injury and illness; identify characteristics related to known gear interactions; share expertise and knowledge about what can be learned from obtaining whole carcasses for examination. The morning also provided a fun, open and inviting platform to get to know one another in a unique professional setting, which was followed by an afternoon discussion.

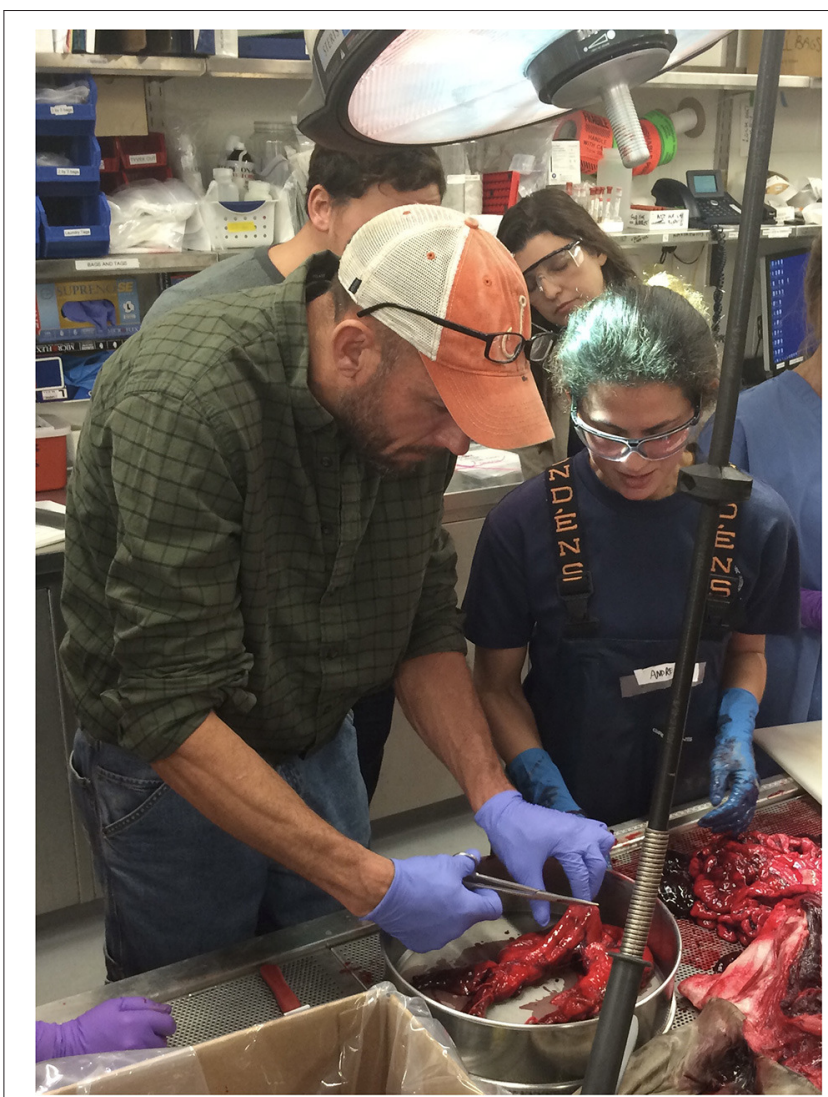

FIGURE 2 | Participants take part in the necropsy of stranded and bycaught seals. Here, a commercial fisherman works on opening the stomach of one of the bycaught gray seals recovered from a gillnet.

\section{Day 2 Summary}

The necropsy session included examination of seal stomach contents, leading to identification of prey (hake and squid) consumed by a harbor seal caught in a gillnet. Stranding personnel learned to identify fish prey with the help of fishermen and Northeast Fisheries Observer Program (NEFOP) staff and observers. There were several useful moments of unplanned information sharing, including an impromptu crash course for fishermen and observers on zoonotic pathogens and the simple strategies used by stranding personnel during field necropsies that might be useful for safely handling marine mammal bycatch aboard fishing vessels.

Following the necropsy, an afternoon discussion initially focused on operational interactions between seals and fisheries. Fishermen posed questions regarding seal diet, and whether seals are attracted to fishing activity or simply the food resources present around the fishing gear. Discussion from a management perspective included potential mitigation measures (i.e., acoustic deterrents) to reduce seal interactions. When asked about incentives for bringing seal carcasses in for study, or allowing researchers on board to study carcasses at sea, fishermen again highlighted the importance of starting with a small group to build mutual trust and understanding. The potential utility 
of a specialized knife or other disentanglement tool to allow fishermen to safely free entangled seals without injury, in particular to avoid seals tearing out of gillnets while retaining a life-threatening "necklace" of netting, was discussed at length.

Fishermen noted that depredation of targeted catch was more costly than gear damage. The need was highlighted for more quantitative and qualitative, standardized data collection to document depredation and the associated catch loss. Studies quantifying depredation are extremely limited in the northeast (Rafferty et al., 2012; Sirak, 2015). Further discussion focused on studies of seal attraction and habituation to fishing gear, learning from bycatch events to inform modification to fishing gear, and the potential formation of a small, confidential working group of scientists and fishermen to study some of the above issues. It was pointed out that causes of seal/ fishery interactions likely involve multiple factors and consequently may require multiple mitigation measures. Fishermen expressed concern regarding the management implications of the findings of collaborative research, but embraced the value of building relationships between communities, sharing knowledge, and establishing trust. In order to inform public perceptions, the group agreed that more education was needed, and fishermen encouraged an interpretive presence at the Chatham Fish Pier.

Discussions between fishery observers and stranding network staff also proved fruitful. The group recognized that data collection on seals is not currently standardized among the two government programs, and discussions began regarding possible means to standardize data collection and analysis to increase the utility of both sets of data on seal injury and mortality. It was recognized that the fishery observer program's fishing gear training materials would be a useful resource for those assessing signs of injury in stranded carcasses, and that in general, cross-training between both programs would be extremely useful.

Methods to improve documentation of entangled/injured seals on haul-out sites and to better quantify injury and mortality using observer data were also discussed. Observer program staff expressed eagerness to collaborate and to provide data and samples, but also highlighted capacity limitations to collect data in field conditions, as well as the logistical challenges of bringing in samples, especially whole carcasses. Stranding network staff offered to assist with sample transport and storage. Representatives of both programs discussed sharing resources. In general, the need was highlighted for increased communication between all participants, and in particular among those in the government programs. Discussion also focused on human health issues and the challenges of messaging to the public and fishing community regarding risks and hazards associated with zoonotic disease.

Finally, the value in retrieving whole carcasses from fishery bycatch was highlighted. Studies of whole carcasses lead to improved understanding of seal diet, life history, and overall health. These cases could also be used to monitor ecosystem and animal health through surveillance of emerging pathogens and stressors of concern.

In order to benefit from what we learn from whole animal carcasses, involving fishermen and observers from the beginning of research was determined to be essential. Incentives for fishermen to bring back these animals to the dock with and without observers (under proper permitting) was discussed. Ideas from participants included more outreach, involvement, communication between all user groups. Ways to reduce negative public perception biases toward fishermen brought on by collaborative research of bycaught animals included simple solutions such as specially designed duffle bags to bring carcasses off vessels for research purposes.

\section{DISCUSSION}

Workshop participants stressed the need for cross-training and regular engagement as a way to share perspectives and experiences between communities. Some of the challenges described included understanding the pressures on fishing families and the larger industry, the need to address welfare considerations of bycaught marine mammals, and the regulatory guidelines which dictate the actions, and sometimes limitations, of management.

Specific recommendations included: standardization of data collection protocols and wider sharing of data related to anthropogenic injury or death to seals, increased opportunities to share knowledge across communities, retrieval of more whole carcasses from fishery bycatch, and working with marine mammal rehabilitation facilities to study live seals. Observations shared during group discussion included: the recognition that working with others to reduce seal bycatch and depredation benefits fishermen, and that fishermen want to be involved in research on and mitigation of seal-fisheries interactions. Many participants expressed positive feedback regarding this workshop, specifically on the objective of providing a successful forum to foster open communication and trust.

\section{Collaborations Resulting From the Workshop}

The value of this workshop can be seen in the diversity of participants engaging with each other years after the workshop. Many of these projects required time to obtain grants, permits and strengthen relationships. A letter of authorization was obtained from the NOAA NEFSC Protected Species Branch in Woods Hole for fishermen to recover seal carcasses resulting from bycatch events without having an observer on board. This initial step has had wide-reaching implications, as new data has been generated on seal diet relative to fishery catch, as well as the recovery of satellitetagged seal carcasses along with the tags themselves. A team of fishermen and scientists began a project using multiple methods to document interactions between gillnets and marine life, including underwater video cameras mounted on fishing gear, on-deck documentation of depredation, and analysis of stomach contents from bycaught seals (Bogomolni et al., 2019). Similarly, other fishermen have begun to experiment with acoustic deterrent devices in commercial fisheries, in collaboration with researchers under guidelines from NOAA. Education and outreach recommendations from this meeting 
included a new interpretive education collaboration at the Chatham Fish Pier between three organizations.

\section{Acknowledgment of Any Conceptual or Methodological Constraints}

Collaboration is a vital solution to coexistence. There are three factors that emerged which prevent more collaborative work to solve seal-fishery conflicts from taking place: 1) Power dynamics, 2) Risk Aversion and 3) Capacity.

\section{Power Dynamics}

A critical observation made during this process was that topdown approaches to conservation often create more conflict than seeking solutions inclusively from on-the-ground constituents (Lute et al., 2020). Organizational structure of conservation and resource management agencies is often compartmentalized, siloed and creates a power dynamic, hindering progress toward open dialogue and collaborative solutions to resolve conflict. Unless concerted effort is made for interdisciplinary collaboration and communication, conversations may be lacking critical perspective. In order to fully understand the challenges and develop solutions, improved communication and relationship-building between those who regulate activities pertaining to both seals and fisheries, as well as actors within their community, is needed. Such engagement amplifies the value of all actors and empowers the community to collaboratively participate in the problem-solving process. Rebounding marine mammal species create complex human dimension perception issues that require multidisciplinary and creative solutions at all levels of conflict (Pooley et al., 2017). Responsibilities of species protection and recovery should be coupled with amplifying the value and role of all community actors, empowering participants, and promoting innovative solutions that minimize conflict.

\section{Risk Aversion}

Perception of risk among and between stakeholder groups and individual actors can prevent action. Fears often prevent discussion or initiation of collaboration. For example, scientists may fear data being misinterpreted, stranding personnel may fear misunderstandings of their efforts toward animal welfare as dismissive to human welfare. Fishermen may sometimes be judged by other fishermen for working with scientists, conservation NGOs and managers. There may be a perception of risk if the public were to see fishermen bring in a dead seal to a public dock. There also may be a fear that science will be used against the fishermen in management. This mistrust in management can extend to mistrust in science, often conflating managers and scientists as the same entity.

\section{Capacity}

In the U.S., government funding directed toward particular marine mammal species is heavily weighted to those listed under the Endangered Species Act (ESA), or populations designated as depleted or categorized strategic under the MMPA, as well as assessing, monitoring, and minimizing threats to populations (Marine Mammal Commission, 2017), with little emphasis or support for interdisciplinary solutions needed to address rebounding protected species. While there have been decades to prepare for this predictable shift in baseline resulting from species protection and recovery efforts, less effort from management agencies has focused on developing mechanisms for the community to resolve conflicts that arise, increasing divisiveness (Guerra, 2019). Similarly, increasing the value of community science and authentic interdisciplinary partnerships would also increase capacity. This could translate as an increase in human dimension research support, in conjunction with applied scientific research to value expertise, knowledge, and a community science approach for rebounding protected species issues.

Supporting partners in this effort also means recognizing the need for general operating budgets, direct compensation and flexible timelines to address challenges and costs associated with vessel and equipment maintenance, weather delays, and unpredictable fishery dynamics (species abundance/distribution). Researchers need to account for the time it takes to engage with the community, and fishermen may require compensation for lost fishing opportunities.

\section{Recommendations}

In order to address rebounding marine mammal-fishery conservation conflicts, we recommend the following:

1) Address the Disconnect. The best lesson learned is one that serves us all well, "just listen." It is easy to be ready with an answer, a solution pre-baked before a conversation is even initiated. Listen, and be ready to be uncomfortable. Understand and acknowledge who is missing at the table as well as who is present, and strive for more inclusion. Ensure all actors have the opportunity to be heard and recognized. Scientists do not necessarily have facilitation training. Enlist a professional facilitator, work with social scientists and increase the skillset among scientists to include facilitation, communication, and conflict resolution.

2) Create Opportunity. Establish more opportunities for actors to engage with each other in a manner that is perceived as a shared benefit in knowledge. Create avenues to put new ideas into process, and opportunities to create dialogue to increase tolerance and mutual respect. Allow the opportunity for community partners to participate in scientific research, as well as for scientists to understand how local knowledge is gained. In our example, we recognized that decisions about fishing interactions with marine mammals were being made by some actors without an understanding of fishing practices. We also recognized that there was little opportunity for fishermen to interact directly with marine mammals and those who work with them in a way that was not about enforcement or provided beneficial knowledge.

3) Communicate and Commit. Initiate dialogue and follow through. It is the responsibility of workshop conveners to facilitate and clarify perspectives when appropriate. This open communication can help to dispel myths and improve information accuracy. As a convener, do not initiate recommendations without transparent communication among all participants throughout the process. As 
recommendations become actions, this ensures that all actors' input has been considered.

4) Increase Awareness. Bring the challenges identified by community to the attention of the public, policymakers and government. Appropriation of funding to address rebounding marine mammal species conflict issues could help foster collaborations. These efforts can be defined within the goals of the MMPA to maintain ecological stability through an ecosystem based management framework. This should include a high priority on human dimension research, education, outreach and efforts to mitigate bycatch.

\section{CONCLUSIONS}

While on the surface the seal-fishery conflict described herein presents solely as a human-animal conflict issue, the challenge is heightened by the tensions within and between human communities (Nyhus, 2016; Guerra, 2019; Blount-Hill, 2021). Like most human-wildlife conflicts, the issue begins with biases and assumptions, perceptions, and in this case, the historical context of the dilemma (Dickman, 2010; Madden and McQuinn, 2015; Burt et al., 2020). When conservation success results in rapid change, some actors will seek familiarity, standing firm on a baseline founded upon what was known in their cumulative lifetime, and not current or emergent situations. Distrust then leads to decreasing engagement and hampering seeking of and implementing solutions to reduce conflicts (Cook, 2015).

To overcome distrust, marine conservation challenges require commitment. The groundwork for this workshop began years before implementation. A comprehensive approach to addressing seal issues started in 2006, nearly a decade prior to this meeting, with local fishing partners reaching out to seal scientists in response to concerns by commercial fishermen and an increase in seals. The workshop discussed herein took place in 2015, and we are currently planning a follow-up workshop (2021) to continue discussions, integrate new actors, update information and update strategies. This long term commitment was critical for past success and will continue to be for the future.

Conservation success is dependent on human behaviors and investment and coordination within local communities. Management of natural resources and their ecosystems require broad and meaningful community engagement, and decisionmaking pertaining to the conservation and protection of natural resources and ecosystems needs to be inclusive of the communities living, operating, and relying economically on resources within these ecosystems. Funding opportunities that incentivize inclusivity, both in the context of methods and results, of members of the local communities add value to, and elevate regional impact of, the work being conducted. Collaborative research programs and requirements for public outreach in planned activities provide opportunities for increased community engagement through communication and connecting the science, as well as increasing interest and awareness; however, conservation solutions for coexistence need involvement of the people within an ecosystem at all stages of planning and implementation process in order to be successful.
Coexistence is not the absence of conflict, and where there are humans with different experiences, and with different attitudes and perceptions about seals, there will be conflict. However, there are hopeful changes in how we address and perceive these challenges. During a recent webinar presentation on seals (Seacoast Science Center, 2020), the lead panelist from the marine mammal stranding field recounted their experience from this workshop six years prior where they watched a commercial fisherman open the stomach of a bycaught seal, betting to find a belly full of his target species (cod), only to discover a nontarget-species (hake). While this fisherman lost the bet, in that moment, everyone won a new appreciation, and a concrete experience that continues to be shared with others, allowing the conversation to shift, and the visualization of a new way to work toward coexistence.

\section{DATA AVAILABILITY STATEMENT}

The original contributions presented in the study are included in the article/supplementary material, further inquiries can be directed to the corresponding author.

\section{ETHICS STATEMENT}

Written informed consent was obtained from the individual(s) for the publication of any potentially identifiable images or data included in this article.

\section{AUTHOR CONTRIBUTIONS}

All authors listed have made a substantial, direct and intellectual contribution to the work, and approved it for publication.

\section{FUNDING}

We thank the M. S. Worthington Foundation for financial support for this workshop. Outreach and engagement leading up to the workshop was supported in part by the Cape Cod Five Cents Savings Bank Charitable Foundation and the Sailors' Snug Harbor Foundation of Boston.

\section{ACKNOWLEDGMENTS}

We wish to thank all participants and presenters for their contributions to the workshop. Lisa Sette (Center for Coastal Studies) assisted with the 'traveling roadshow' outreach and engagement process, an idea originally proposed by Sharon Young. We owe a special thanks to Amy Martins and the staff of the Northeast Fisheries Observer Program for providing training materials and helping to lead the fishing gear demonstrations. Chatham fisherman Doug Feeney made fishing vessels and gear available for demonstrations, and Mo Bancroft from the Cape Cod Commercial Fishermen's Alliance assisted in bringing fishermen to the table. Many thanks to Frederick Wenzel at Northeast Fisheries Science Center for coordinating bycatch 
for necropsy. The Chatham Community Center staff and Betty Lentell helped with Day 1 logistics. Misty Niemeyer and the International Fund for Animal Welfare Marine Mammal Rescue program provided a stranded seal and training support during the necropsy on Day 2. John Murphy Jr. graciously allowed us to use a room at the Land Ho! Restaurant in Orleans for our evening discussions and dinner. We wish to thank the Northwest Atlantic Seal Research Consortium community for creating and

\section{REFERENCES}

Blount-Hill, K.-L. (2021). Proposing a social identity theory of interspecies dominance. Biol. Conserv. 254:108969. doi: 10.1016/j.biocon.2021.108969

Bogomolni, A., Early, G., Matassa, K., Nichols, O., and Sette, L. (2010). Gulf of Maine seals- populations, problems and priorities. Woods Hole Oceanographic Institution Technical Report 2010-06. Available online at: https://hdl.handle.net/ 1912/3701 (accessed March 16, 2021).

Bogomolni, A., Nichols, O. C., Bocconcelli, A., Sette, L., Wenzel, F., Hernandez, K. M., et al. (2019). Characterizing bycatch and depredation in northeast U.S. sink gillnet fisheries [Conference presentation]. Barcelona, Spain: World Marine Mammal Conference. https://www.wmmconference.org/wp-content/uploads/ 2020/02/WMMC-Book- of-Abstracts.pdf (accessed March 16, 2021).

Boston Magazine (2013). Cape Cod's Seal Problem. https://www.bostonmagazine. com/news/2013/06/25/gray-seal-population-problem-cape-cod (accessed March 16, 2021)

Burt, J. M., Wilson, I. B. J., Malchoff, T., Mack, W. T. K. A., Davidson, S. H. A., and Salomon, A. K. (2020). Enabling coexistence: navigating predatorinduced regime shifts in human-ocean systems. People Nat. 2, 557-574. doi: $10.1002 /$ pan3.10090

Cammen, K. M., Rasher, D. B., and Steneck, R. S. (2019). Predator recovery, shifting baselines, and the adaptive management challenges they create. Ecosphere 10:e02579. doi: 10.1002/ecs2.2579

Charles, A., Loucks, L., Berkes, F., and Armitage, D. (2020). Community science: a typology and its implications for governance of social-ecological systems. Environ. Sci. Policy 106, 77-86. doi: 10.1016/j.envsci.2020. 01.019

Cook, K. S. (2015). "Institutions, trust, and social order," in Order on the Edge of Chaos: Social Psychology and the Problem of Social Order, eds E.J Lawler, J. Yoon, S.R. Thye (United Kingdom: Cambridge University Press), 125-144. doi: 10.1017/CBO9781139924627.008

Dickman, A. J. (2010). Complexities of conflict: the importance of considering social factors for effectively resolving human-wildlife conflict. Anim. Conserv. 13, 458-466. doi: 10.1111/j.1469-1795.2010.00368.x

Götz, T., and Janik, V. M. (2013). Acoustic deterrent devices to prevent pinniped depredation: efficiency, conservation concerns and possible solutions. Mar. Ecol. Prog. Ser. 492, 285-302. doi: 10.3354/meps 10482

Guerra, A. S. (2019). Wolves of the sea: managing human-wildlife conflict in an increasingly tense ocean. Mar. Policy 99, 369-373. doi: 10.1016/j.marpol.2018.11.002

Gulland, J. A. (1986). Marine mammal-fisheries interactions. Ambio 15, 152-154.

Hayes, S. A, Josephson, E., Maze-Foley, K., and Rosel, P. E. (2019). US Atlantic and Gulf of Mexico Marine Mammal Stock Assessments2018. In: NOAA Technical Memorandum NMFS-NE. (Woods Hole: US Department of Commerce), 258. doi: 10.org/10.25923/9rr d-tx13

Jackman, J., Bettencourt, L., Vaske, J., Sweeney, M., Bloom, K., Rutberg, A., et al. (2018). Conflict and consensus in stakeholder views of seal management on Nantucket Island, MA, USA. Mar. Policy 95, 166-173. doi: 10.1016/j.marpol.2018.03.006

Katona, S. K., Rough, V., and Richardson, D. T. (1993). A Field Guide to Whales, Dolphins, and Seals from Cape Cod to Newfoundland. Washington, DC. Smithsonian Institution Press. maintaining a space to continue conversation and collaboration. Jennifer Jackman (Salem State University) provided helpful insight into human dimensions research. We wish to thank the Frontiers Special Issue editors for encouraging us to submit this paper and the reviewers for their helpful suggestions. Finally, we wish to thank Doug Feeney and all fishing community members who have been willing to boldly challenge assumptions, break down barriers, and try new approaches.

Lelli, B., Harris, D. E., and Aboueissa, A.-M. (2009). Seal bounties in Maine and Massachusetts, 1888 to 1962. Northeast. Nat. 16, 239-254. doi: 10.1656/045.016.0206

Lute, M. L., Carter, N. H., López-Bao, J. V., and Linnell, J. D. (2020). Conservation professionals' views on governing for coexistence with large carnivores. Biol. Conserv. 248:108668. doi: 10.1016/j.biocon.2020.108668

Madden, F., and McQuinn, M. (2015). "Understanding social conflict and complexity in marine conservation," in Human-Wildlife Conflict: Complexity in the Marine Environment, eds M. Draheim, F. Madden, J.-B. McCarthy, E.C.M. Parsons (Oxford, UK: Oxford University Press), 3-16. doi: 10.1093/acprof:oso/9780199687145.003.0001

Marine Mammal Commission (2017). Survey of Federally-Funded Marine Mammal Research and Conservation. Bethesda, MD: Marine Mammal Commission.

Nantucket Chronicle (2013). Gray Seals vs. Fishermen, Sharks, Environmentalists and the Easter Bunny. Available online at: https://www.nantucketchronicle. com/outdoors/2013/gray-seals-vs-fishermen-sharks-environmentalists-andeaster-bunny (accessed March 16, 2021)

Nichols, O. C. (2011). Involve fishermen from the start to build strong research partnerships. Commer. Fish. News 38:24.

Nichols, O. C., Bogomolni, A., Bradfield, E., Early, G., Sette, L., and Wood, S. (2012). Gulf of Maine seals- fisheries interactions and integrated research. Woods Hole Oceanographic Institution Technical Report 2012-06. Available online at: https://hdl.handle.net/1912/5514 (accessed March 16, 2021).

Nichols, O. C., Eldredge, E., and Cadrin, S. X. (2014). Gray seal behavior in a fish weir observed using Dual-frequency Identification Sonar. Mar. Technol. Soc. J. 48, 72-78. doi: 10.4031/MTSJ.48.4.2

Northeast Fisheries Science Center (2020). State of the Ecosystem 2020: MidAtlantic. Available online at: https://repository.library.noaa.gov/view/noaa/ 23889 (accessed March 16, 2021).

Nyhus, P. J. (2016). Human-wildlife conflict and coexistence. Annu. Rev. Environ. Resour. 41, 143-171. doi: 10.1146/annurev-environ-110615-085634

Plagányi, E. E., and Butterworth, D. S. (2005). "Indirect fishery interactions," in Marine Mammal Research: Conservation Beyond Crisis, eds J. E. Reynolds III., W. F. Perrin, R. R. Reeves, S. Montgomery and T. J. Ragen (Baltimore, MD: Johns Hopkins University Press), 19-45.

Pooley, S., Barua, M., Beinart, W., Dickman, A., Holmes, G., Lorimer, J., et al. (2017). An interdisciplinary review of current and future approaches to improving human-predator relations. Conserv. Biol. 31, 513-523. doi: 10.1111/cobi.12859

Rafferty, A. R., Brazer Jr, E. O., and Reina, R. D. (2012). Depredation by harbor seal and spiny dogfish in a Georges Bank gillnet fishery. Fisheries Manag. Ecol. 19, 264-272. doi: 10.1111/j.1365-2400.2011. 00837.x

Read, A. J. (2005). "Bycatch and depredation," in Marine Mammal Research: conservation Beyond Crisis, eds J. E. Reynolds III., W. F. Perrin, R. R. Reeves, S. Montgomery and T. J. Ragen (Baltimore, MD: Johns Hopkins University Press), 5-17.

Read, A. J. (2008). The looming crisis: interactions between marine mammals and fisheries. J. Mammal. 89, 541-548. doi: 10.1644/07-MAMM-S-315R1.1

Read, A. J., Drinker, P., and Northridge, S. (2006). Bycatch of marine mammals in U.S. and global fisheries. Conserv. Biol. 20, 163-169. doi: $10.1111 /$ j.1523-1739.2006.00338.x 
Redpath, S. M., Young, J., Evely, A., Adams, W. M., Sutherland, W. J., Whitehouse, A., et al. (2013). Understanding and managing conservation conflicts. Trends Ecol. Evol. 28, 100-109. doi: 10.1016/j.tree.2012. 08.021

Roman, J., Dunphy-Daly, M. M., Johnston, D. W., and Read, A. J. (2015). Lifting baselines to address the consequences of conservation success. Trends Ecol. Evol. 30, 299-302. doi: 10.1016/j.tree.2015.04.003

Salomon, A. K., Lertzman, K., Brown,K., Wilson,K. B., Secord, D., and McKechnie, I. (2018). Democratizing conservation science and practice. Ecol. Soc. 23, 44. doi: 10.5751/ES-09980-230144

Schmeer, K. (1999). Guidelines for Conducting a Stakeholder Analysis. Bethesda, MD: Partnerships for Health Reform, Abt Associates Inc.

Seacoast Science Center (2020). Systems in Balance: Seals and Sharks in New England. Available online at: https://www.seacoastsciencecenter.org/ workshops/systems-in-balance/ (accessed March 16, 2021)

Sirak, L. N. (2015). Grey (Halichoerus grypus) and Harbor Seal (Phoca vitulina) Bycatch and Depredation in New England Sink-Gillnet Fisheries (Master's thesis). Biddeford, ME: University of New England. Available online at: https://dune. une.edu/theses/120/ (accessed March 16, 2021).

Wood, S. A., Murray, K. T., Josephson, E., and Gilbert, J. (2020). Rates of increase in gray seal (Halichoerus grypus atlantica) pupping at recolonized sites in the United States, 1988-2019. J. Mammal. 101, 121-128. doi: 10.1093/jmammal/gyz184
Zimmermann, A., McQuinn,. B., and Macdonald, D. W. (2020). Levels of conflict over wildlife: understanding and addressing the right problem. Conserv. Sci. Pract. 2:e259. doi: 10.1111/ $\operatorname{csp} 2.259$

Conflict of Interest: The authors declare that the research was conducted in the absence of any commercial or financial relationships that could be construed as a potential conflict of interest.

Publisher's Note: All claims expressed in this article are solely those of the authors and do not necessarily represent those of their affiliated organizations, or those of the publisher, the editors and the reviewers. Any product that may be evaluated in this article, or claim that may be made by its manufacturer, is not guaranteed or endorsed by the publisher.

Copyright (C) 2021 Bogomolni, Nichols and Allen. This is an open-access article distributed under the terms of the Creative Commons Attribution License (CC BY). The use, distribution or reproduction in other forums is permitted, provided the original author(s) and the copyright owner(s) are credited and that the original publication in this journal is cited, in accordance with accepted academic practice. No use, distribution or reproduction is permitted which does not comply with these terms. 